\title{
CONSTRUÇÃO E VALIDAÇÃO DE UM ÍNDICE PARA AVALIAR O CLIMA ORGANIZACIONAL: ESTUDO DE CASO EM UMA EMPRESA VAREJISTA FORMIGUENSE
}

\author{
Maycon Mayk Bento ${ }^{1}$ \\ Lélis Pedro de Andrade ${ }^{2}$ \\ Aline de Paula Fonseca ${ }^{3}$ \\ Bruna Antunes Tavares Ribeiro ${ }^{4}$ \\ Karen Cristine Mendonça Gonçalves 5 \\ Nágila Giovanna Silva Vilela ${ }^{6}$ \\ Samara Maria Pires ${ }^{7}$ \\ Robson de Castro Ferreira ${ }^{8}$
}

\begin{abstract}
RESUMO
O estudo do clima organizacional é relevante para todos os tipos de empresas, independente de seu porte, pois exerce influência na eficiência e no desenvolvimento da organização. Para esta pesquisa realizou-se uma revisão sistemática da literatura com o objetivo de subsidiar a construção e validação de um índice para avaliação do clima organizacional, por meio de um estudo de caso em uma empresa de varejo na cidade de Formiga - MG. Para atingir o objetivo proposto foi desenvolvido um questionário visando reduzir a subjetividade do modelo de Kolb (KOLB et al.,1986). Os testes estatísticos Kaiser-Meyer-Olkin (KMO) e Alpha de Cronbach foram aplicados e dentre as questões propostas para as sete dimensões do modelo, apenas aquelas pertencentes a cinco dimensões apresentaram resultados válidos: clareza organizacional, responsabilidade, liderança, padrões e recompensas. Como forma de subsidiar a tomada de decisão do gestor foram desenvolvidos dois modelos de regressão, nos quais utilizou-se o índice score (soma das médias das notas obtidas em cada dimensão do modelo) como variável dependente e os constructos selecionados por meio da Análise dos Componentes Principais como variáveis explicativas. Por meio da análise dos modelos de regressão desenvolvidos identificou-se que dentre os variados aspectos do clima organizacional estudados, os constructos pertencentes às dimensões "liderança" e "padrões" foram os que apresentaram maior sensibilidade no clima organizacional, sendo, portanto, as dimensões mais relevantes e que requerem mais atenção por parte dos gestores.
\end{abstract}

1 Graduando em Administração pelo IFMG-Campus Formiga. E-mail: mayconcrc13@ @otmail.com

2 Doutor em Administração/Finanças pela Universidade Federal de Minas Gerais (UFMG), mestrado e graduação em Administração/Finanças pela Universidade Federal de Lavras (UFLA) e professor no Instituto Federal de Minas Gerais (IFMG) Campus Formiga. E-mail: lelis.pedro@ifmg.edu.br.

3 Graduando em Administração pelo IFMG-Campus Formiga. E-mail: alinepaula456@ hotmail.com.

4 Graduanda em Administração pelo IFMG-Campus Formiga. E-mail: bruni_antunes@ @otmail.com.

5 Graduanda em Administração pelo IFMG-Campus Formiga. E-mail: karen.2309@ hotmail.com.

6 Graduanda em Administração pelo IFMG-Campus Formiga. E-mail: nagilavilela@gmail.com.

7 Graduanda em Administração pelo IFMG-Campus Formiga. E-mail: samara-pires@ hotmail.com.

8 Mestre em Administração pela UFLA, graduação em Administração pela UFLA e professor do IFMG Campus Formiga. E-mail: robson.ferreira@ifmg.edu. 
Palavras-chave: Clima organizacional. Modelo de Kolb. Estatística multivariada. Análise dos componentes principais. Regressão.

\title{
CONSTRUCTION AND VALIDATION OF AN INDEX TO EVALUATE THE ORGANIZATIONAL CLIMATE: A CASE STUDY IN A COMPANY RETAIL FORMIGUENSE
}

\begin{abstract}
The study of organizational climate is relevant to all types of organizations, regardless of their size, because it influences the efficiency and development of the organization. For this research we carried out a systematic review of the literature in order to subsidize the construction and validation of an index to evaluate the organizational climate, through a case study in a retail company in Formiga - MG. To achieve this purpose a questionnaire was developed to reduce the subjectivity of the Kolb (KOLB et al., 1986) model. Statistical tests Kaiser-Meyer-Olkin (KMO) and Cronbach's Alpha were applied and among the issues proposed for the seven model dimensions, only those belonging to five dimensions had valid results: organizational clarity, accountability, leadership, standards and rewards. As a way to support the manager's decision two regression models were developed, in which we used the score index (sum of the average of the marks obtained in each dimension of the model) as the dependent variable and the constructs selected by Principal Component Analysis as explanatory variables. By analyzing the developed regression models it was identified that among the various aspects of organizational climate studies, the constructs belonging dimensions "leadership" and "standards" were those with the highest sensitivity in the organizational environment, and therefore are relevant dimensions that require more attention by managers.
\end{abstract}

Keywords: Organizational climate. Kolb model. Multivariate statistics. Principal component analysis. Regression.

\section{INTRODUÇÃO}

A presente pesquisa trata da construção e da validação de um índice para avaliar o clima organizacional. De acordo com Santos et al. (2010), o clima organizacional está relacionado diretamente com o modo com que os funcionários compreendem e interpretam a empresa por meio de sua cultura, normas, costumes, além de permitir a percepção de como estes reagem positiva ou negativamente à interpretação.

Sbragia (1983) definiu alguns aspectos para o entendimento do clima organizacional. De acordo com o autor, o clima organizacional é uma variável interveniente ou propriedade subjetiva e é afetado pelas propriedades objetivas do ambiente organizacional como: necessidades das pessoas, estrutura organizacional, estilos de liderança, estratégias motivacionais, entre outros. Além disso, o clima de uma empresa colabora para que fatores de 
eficácia e/ou desempenho sejam alcançados como produtividade, qualidade de trabalho, satisfação, absenteísmo e rotatividade.

Diante à subjetividade envolta ao estudo do clima organizacional, o objetivo da pesquisa é construir e validar um índice para avaliar o clima organizacional. Para atingir esse objetivo foi utilizado o modelo de pesquisa de clima organizacional de Kolb et al. (1986) como modelo para validação das questões. O modelo é composto por sete dimensões: conformismo, responsabilidade, padrões, recompensas, clareza organizacional, calor e apoio, liderança, as quais buscam identificar variados fatores relacionados ao clima organizacional.

Esta pesquisa justifica-se pela relevância de estudos voltados ao clima organizacional, visto a influência deste na competitividade empresarial, a produtividade e a qualidade de vida no trabalho (LUZ, 2003). Além disso, a proposta de uma abordagem prática de estudo como forma de amenizar a subjetividade da temática.

\section{REFERENCIAL TEÓRICO}

\subsection{Clima organizacional e sua importância para as empresas}

O estudo do clima organizacional apresentou uma maior difusão no âmbito científico na década de 70 (SOUZA, 1980). Este autor ainda menciona que o termo "clima" é utilizado e compreendido facilmente, porém, sob o aspecto científico, sua definição torna-se mais complexa, contribuindo para a propagação de distintas conceituações (SOUZA, 1982).

Nesse sentido, Sbragia (1983), afirma que o clima trata de um termo amplo que possibilita o agrupamento de variadas percepções em um limitado número de dimensões, podendo ser utilizado para descrever organizações, caracterizar percepções ou descrever sistemas sociais. $\mathrm{O}$ autor ressalta que como forma de descrever as percepções dos indivíduos sobre as empresas em que trabalham, o clima organizacional tem se tornado um conceito cada vez mais relevante e reconhecido.

O clima organizacional está relacionado diretamente com o modo com que os funcionários compreendem e interpretam a empresa por meio de sua cultura, normas, costumes, além de permitir a percepção de como estes reagem positiva ou negativamente à interpretação (SANTOS et al., 2010). Para Pasetto e Mesadri (2012, p. 105), apesar das inúmeras conceituações, em todas elas é possível perceber que “[...] o clima representa as 
percepções que os empregados têm dos valores compartilhados, os quais se tornam tangíveis por meio das ações que são tomadas nas empresas".

A importância do clima organizacional no comportamento da organização é uma questão há muito estudada. De forma geral, pode-se dizer que estudar o clima organizacional, permite mensurar e caracterizar a satisfação dos funcionários em relação ao seu trabalho (SANTOS et al., 2010). Laros e Puente-Palacios (2004), também apresentam a relevância desse tema ao mencionarem a sua influência tanto no comportamento como no desempenho dos funcionários, e como este pode refletir na competência da empresa.

A investigação do clima organizacional contribui em variados aspectos tanto teóricos quanto práticos. No sentido teórico, tem-se por meio de uma ampla análise de elementos relevantes, um aprofundamento acerca do estudo do funcionamento da empresa. Tratando do aspecto prático, observa-se através da investigação do tema, a oportunidade de avaliar os estilos de liderança, situações de ineficiência e ineficácia, entre outros. Tendo como resultado uma maior possibilidade de interferência na organização (LEITÃO et al., 1998 apud PAYNE; MANSFIELD, 1977).

\subsection{O modelo de Kolb para avaliação do clima organizacional}

Variados modelos foram desenvolvidos a fim de proporcionar o estudo do clima organizacional que tem o objetivo de medir os níveis de satisfação dos colaboradores no que diz respeito a aspectos do ambiente organizacional e a interação das pessoas na organização. A avaliação do clima organizacional pode ser feita por meio da tradução da "[...] motivação, satisfação e a qualidade do ambiente interno da empresa que é percebida pelos funcionários, trazendo a percepção, aspectos positivos e negativos, permitindo assim a identificação de oportunidades de melhorias no clima da empresa" (CARVALHO, 2011, p. 32-33).

Desta forma, buscando desenvolver uma metodologia de estudo do clima organizacional, Kolb et al. (1986) propõe o seguinte modelo/escala com sete fatores relacionados à temática, conforme o Quadro 1: 


\begin{tabular}{|c|c|}
\hline Dimensão & Características \\
\hline Conformismo & $\begin{array}{l}\text { O sentimento advindo da excessiva quantidade de regras, procedimentos e } \\
\text { políticas que limitam a ação dos membros na organização, levando-os ao } \\
\text { conformismo. }\end{array}$ \\
\hline Responsabilidade & $\begin{array}{l}\text { Dever pessoal de cumprir suas tarefas e obrigações de modo a realizarem sua } \\
\text { parte nos objetivos da empresa. Está diretamente relacionada com o grau de } \\
\text { liberdade dos membros de tomar decisões sem terem de verificar sempre com } \\
\text { os superiores. }\end{array}$ \\
\hline Padr & $\begin{array}{l}\text { npresa coloca na qualidade do c } \\
\text { grau que a organização foca em seu }\end{array}$ \\
\hline $\operatorname{Re}$ & $\begin{array}{l}\text { grau em que os membros percebem que estão sendo reconhecidos e } \\
\text { ecompensados pelo seu trabalho. }\end{array}$ \\
\hline $\begin{array}{r}\text { Cla } \\
\text { Organ }\end{array}$ & $\begin{array}{l}\text { Percepção por parte dos membros de que as coisas são bem organizadas e os } \\
\text { objetivos claramente definidos, não havendo confusão entre eles. }\end{array}$ \\
\hline Calor e Apoio & $\begin{array}{l}\text { Valorização da amizade, confiança e do apoio entre os funcionários, } \\
\text { prevalecendo sempre boas relações no ambiente de trabalho. }\end{array}$ \\
\hline Lide & $\begin{array}{l}\text { A disposição dos membros da organização para aceitar a liderança e a direção } \\
\text { de outras pessoas qualificadas, assim como para se tornar líder diante de } \\
\text { situações que exijam liderança. }\end{array}$ \\
\hline
\end{tabular}

Quadro 1 - As 7 dimensões do modelo de Kolb (KOLB et al.,1986) e suas características

Fonte: Autores (2015).

\subsection{As dimensões do clima organizacional}

De acordo com Tagliocolo e Araújo (2011) as dimensões que podem influenciar o ambiente da organização são a resistência à mudança, o estresse, a liderança e a motivação. Em síntese a resistência à mudança é associada à modificação da rotina de trabalho de um colaborador por uma mais hábil e quando inclui a colaboração de outros funcionários na atividade de implantação e adequação de um sistema diferente. O estresse está ligado à falta de produtividade e de motivação do funcionário. A liderança correlaciona o líder com o colaborador, as atitudes que o líder executa influenciam diretamente na motivação de seu funcionário. Já a motivação está mais vinculada com a maneira como o colaborador se comporta quanto aos aspectos internos da organização. A síntese das dimensões pode ser vista no Quadro 2. 


\begin{tabular}{|c|l|c|c|}
\hline Dimensão & \multicolumn{1}{|c|}{ Características } & Referências \\
\hline $\begin{array}{c}\text { Resistência a } \\
\text { Mudanças }\end{array}$ & $\begin{array}{l}\text { A resistência pode ser considerada algo natural dos } \\
\text { indivíduos, ela acontece quando algo é imposto a } \\
\text { determinada mudança, visto que o colaborador pode se sentir } \\
\text { ameaçado por tal. }\end{array}$ & $\begin{array}{c}\text { Tagliocolo e Araújo } \\
(2011)\end{array}$ \\
\hline Estresse & $\begin{array}{l}\text { Pode acontecer do vínculo entre o colaborador e o seu } \\
\text { ambiente de trabalho, ou seja, quando as exigências do } \\
\text { trabalho são maiores que a capacidade do funcionário. }\end{array}$ & $\begin{array}{c}\text { Tagliocolo e Araújo } \\
(2011)\end{array}$ \\
\hline Liderança & $\begin{array}{l}\text { "Capacidade de influenciar um grupo para alcançar metas"1; } \\
\text { "Um processo de influência dirigindo para modelar o } \\
\text { comportamento de outras pessoas"2. }\end{array}$ & $\begin{array}{c}\text { Robbins (2005)1; } \\
\text { Caravantes, Panno } \\
\text { e Kloeckener } \\
(2005)^{2}\end{array}$ \\
\hline Motivação & $\begin{array}{l}\text { Pode ser compreendida como uma energia, uma tensão, uma } \\
\text { força, ou ainda, um impulso interno das pessoas. }\end{array}$ & $\begin{array}{c}\text { Tagliocolo e Araújo } \\
(2011)\end{array}$ \\
\hline
\end{tabular}

Quadro 2 - Dimensões do Clima Organizacional e suas características

Fonte: Autores (2015).

\subsection{O clima organizacional e seu impacto sobre a qualidade dos serviços}

Para que um funcionário execute bem as responsabilidades que lhe foram atribuídas é necessário que: saiba o que fazer (conhecimentos e habilidades), possa fazer (ter e ser capaz de usufruir os recursos necessários) e queira fazer (estado de espírito, ânimo e satisfação para realizar determinada tarefa). O "querer fazer" está diretamente relacionado ao clima organizacional, sendo que muitas vezes as causas da má qualidade dos serviços são encontradas nesse aspecto (LUZ, 2003).

Ainda que a administração do clima seja uma incumbência da Administração de Recursos Humanos, quando tratamos da organização em setores, a responsabilidade aplica-se a quem atua no cargo de gestão, uma vez que compreender as expectativas e necessidades dos funcionários e o nível de satisfação desses é um desafio gerencial e fundamental para o progresso no ambiente de trabalho e aperfeiçoamento dos serviços prestados (SOARES; SOUZA, 2014).

Luz (2003) comenta que muitas organizações se preocupam demasiadamente com seus clientes externos, criando, por exemplo, canais de comunicação Serviço de Atendimento ao Cliente (SAC), porém erram ao esquecer que a satisfação dos clientes externos é fruto da satisfação dos clientes internos. As empresas desprezam a importância presente na comunicação com seus colaboradores e ignoram o fato de que a qualidade dos serviços prestados pode ser melhorada através do investimento na gestão do clima organizacional.

Oliveira, Carvalho e Rosa (2012) indicam três resultados eficazes para a organização que são criados a partir de um bom clima organizacional: produtividade, lucro e motivação. ForSci.: r. cient. IFMG Campus Formiga, Formiga, v. 3, n. 2, p. 03-25, jul./dez. 2015. 
Quando os funcionários estão descontentes, desanimados ou sem motivação para exercer sua função, eles acabam agindo de maneira inadequada, sem se preocupar com a conformidade e precisão de suas tarefas. Muitas vezes, querem apenas a estabilidade no emprego. Se essas ações são praticadas por aqueles que operam na linha de frente da empresa, provavelmente o atendimento ao cliente será insatisfatório (CARVALHO, 2011).

Apesar da dificuldade de mensurar a qualidade dos serviços devido à satisfação dos clientes ser composta por vários fatores intangíveis (FITZSIMMONS; FITZSIMMONS, 2000 apud SIQUEIRA; GODOY, 2003), a melhoria contínua em produtividade e qualidade deve estar presente nas estratégias e na cultura de organizações que queiram manter-se no mercado. A pesquisa de clima organizacional pode contribuir nesse ponto, pois a partir do diagnóstico é possível identificar as falhas que afetam a qualidade dos serviços e em seguida analisar o que pode ser feito para a melhoria do clima organizacional e da própria qualidade (SIQUEIRA; GODOY, 2003).

\section{METODOLOGIA}

\subsection{Descrição do objeto de estudo}

A organização $X$ atua no setor de varejo há mais de 50 anos, sendo uma empresa tradicional na cidade. Durante muitos anos a empresa teve uma administração familiar. Recentemente ocorreram mudanças significativas na gestão da organização, como o enxugamento da estrutura hierárquica e a troca de pessoal no nível estratégico da empresa. De acordo com a percepção dos gestores, tais mudanças impactaram negativamente no clima organizacional. Diante disso, identificou-se a necessidade e importância de verificar a veracidade da impressão dos administradores.

\subsection{Procedimentos metodológicos}

No que diz respeito aos procedimentos metodológicos, utilizou-se o estudo de caso e a pesquisa com survey. O método de coleta de dados é o questionário. O questionário (Apêndice A) foi composto por 51 questões elaboradas pelos autores com base no modelo de Kolb (KOLB et al., 1986). As questões de 1 a 4 referem-se a conformismo; 5 a 15, clareza organizacional; 16 a 21, calor e apoio; 22 a 27, liderança; 28 a 33, responsabilidade; 34 a 38, 
padrões; 39 a 51, recompensas. Os respondentes tiveram cinco opções de resposta que variaram de discordo totalmente a concordo totalmente, conforme a Escala Likert.

A amostra não probabilística, por acessibilidade e/ou conveniência foi formada por 44 respondentes que continham relação de trabalho com a Empresa $\mathrm{X}$ na data de aplicação dos questionários (14/07/2015).

Para análise descritiva dos dados foi utilizada a média e desvio padrão de cada dimensão e também de todos os dados conjuntamente. Como forma de validar os dados levantados, optou-se por aplicar dois testes: o primeiro foi o teste Kaiser-Meyer-Olkin (KMO), o qual demonstra a proporção da variância dos dados que pode ser considerada comum a todas as variáveis, ou seja, indica o grau de adequação da amostra (veja a Tabela 1); e o segundo foi o Alpha de Cronbach, o qual, segundo Santos (1999), caracteriza-se por um índice que busca determinar a correlação média ou consistência interna de um instrumento de pesquisa, validando aqueles que apresentam o alpha maior que 0,7 .

Tabela 1 - Critério de Kaiser-Meyer-Olkin (KMO)

\begin{tabular}{cc}
\hline Valor & Grau de Adequação da Amostra \\
\hline$>0,90$ & Ótima \\
de 0,80 a 0,90 & Boa \\
de 0,70 a 0,80 & Razoável \\
de 0,60 a 0,70 & Baixa \\
$<0,60$ & Inadequada \\
\hline
\end{tabular}

Fonte: Autores (2015).

Devido à grande demanda de informação dos dias de hoje, cada vez mais é necessário que os dados sejam tratados não somente por meio de análises simples, mas também de utilizando técnicas estatísticas multivariadas. Esse tipo de análise permite uma maior extração de informações que geram conhecimentos que e, consequentemente, melhoram a tomada de decisão. Uma pesquisa que analisa múltiplas variáveis simultaneamente pode ser considerada multivariada. Desta forma, a técnica de análise de dados utilizada na presente pesquisa é a análise multivariada, uma vez que as variáveis foram analisadas ao mesmo tempo. Tal análise foi realizada pelo software Stata (HAIR et al., 2009).

Outro aspecto metodológico refere-se à atualização da análise de componentes principais, técnica da estatística multivariada, a qual considera a variância total, derivando os fatores que possuem menores quantidades de variância única ou de erro, ou seja, busca converter um conjunto de variáveis originais em um conjunto de variáveis com mesma 
dimensão denominadas de componentes principais, permitindo assim, uma redução significativa dos dados (VARELLA, 2008; HAIR et al., 2009). Para a seleção dos componentes relevantes presentes em cada dimensão, foi utilizado o critério de KaiserGuttman que permite uma avaliação rápida e objetiva do número de fatores a serem considerados, uma vez que segue uma lógica simples: cada componente mantido apresenta um eigenvalue que significa o total de variância explicada por este fator. Todos os eigenvalues somados são sempre iguais ao número de itens utilizados na análise. Desta forma, um fator com eigenvalue menor que 1 apresenta um total de variância explicada menor do que um único item. Portanto, somente componentes maiores que um são mantidos, visto que o objetivo das análises fatoriais é diminuir o número de variáveis observadas (FLOYD, WIDAMAN, 1995 apud DAMÁSIO, 2012).

E por fim, aplicou-se a análise de regressão robusta. Segundo Demétrio e Zocchi (2006), nos modelos de regressão busca-se relacionar o comportamento de uma variável aleatória Y com uma ou mais variáveis X's por meio de uma função $\mathrm{f}(\mathrm{x})$. É chamado de regressão, pois "existe uma tendência de os dados regredirem à média" (DEMÉTRIO; ZOCCHI, 2006, p. 20).

A adoção do modelo robusto está fundamentada em sua capacidade de produzir estimadores consistentes e razoavelmente eficientes, testes estatísticos com nível estável e influente quando o modelo está ligeiramente mal especificado (HERITIER et al., 2009).

Como forma de validar as variáveis explicativas do modelo, adotou-se a aplicação duas análises validárias: multicolinearidade e significância ( $p$-values).

A multicolinearidade, segundo Coimbra et al. (2005), ocorre quando há determinado nível de inter-relação entre as variáveis independentes. Ressalta-se que uma multicolinearidade possui alguns efeitos específicos quando se eleva, tais como: “[...] estimativa inconsistente do coeficiente de regressão e superestimativa dos efeitos diretos das variáveis explicativas sobre a variável resposta [...]” (CRUZ; CARNEIRO, 2003 apud COIMBRA et al., 2005, p. 348), podendo causar uma interpretação errônea (CRUZ; CARNEIRO, 2003 apud COIMBRA et al., 2005).

\section{RESULTADOS E DISCUSSÕES}

Por meio da análise descritiva dos dados, dentre os fatores relacionados no instrumento de coleta de dados, o nível de concordância mais elevado corresponde à 
dimensão "responsabilidade", uma vez que a média encontrada foi 4,452 e o desvio padrão 0,562. Estes resultados demonstram que os funcionários possuem alto nível de responsabilidade, autonomia e domínio das informações e processos necessários para execução de suas funções. Em contrapartida, a dimensão que apresentou o menor nível de concordância, média de 3,557 e desvio padrão de 0,729 refere-se à dimensão "padrões", ou seja, os resultados demonstram uma ineficiência da organização em priorizar normas, processos e qualidade dos serviços. Este resultado foi significativo, pois teve como base opiniões de um grupo de respondentes de diferentes setores da empresa X.

Tabela 2 - Análise Descritiva dos Dados

\begin{tabular}{cccccccc}
\hline Dimensões & \multicolumn{9}{c}{ Escala9 $^{9}$} & Média & \multirow{2}{*}{ Desvio Padrão } \\
\hline Conformismo & 1 & 2 & 3 & 4 & 5 & & \\
Clareza organizacional & 30 & 39 & 20 & 136 & 234 & 4,100 & 0,818 \\
Calor e apoio & 10 & 21 & 9 & 93 & 117 & 4,144 & 0,641 \\
Liderança & 9 & 31 & 13 & 59 & 139 & 4,147 & 0,751 \\
Responsabilidade & 7 & 13 & 3 & 64 & 163 & 4,452 & 0,562 \\
Padrões & 19 & 42 & 13 & 75 & 61 & 3,557 & 0,729 \\
Recompensas & 39 & 49 & 18 & 143 & 284 & 4,096 & 0,630 \\
\hline Geral & & & & & 4,074 & 0,680 \\
\hline
\end{tabular}

Fonte: Autores (2015).

Para a análise dos componentes principais, incialmente foram realizados dois testes de validação dos constructos referentes a cada dimensão do modelo (Tabela 2).

Utilizando como base o "critério de Kaiser-Meyer-Olkin", conforme os parâmetros exibidos na Tabela 1, percebe-se que as dimensões "conformismo" e "calor e apoio" apresentaram um grau de adequação inadequada (0,56 e 0,59, respectivamente) - portanto, estas foram excluídas da análise. As dimensões "liderança", "responsabilidade" e "padrões" apresentaram um grau de adequação baixo $(0,6278,0,6298$ e 0,6792, respectivamente), e as dimensões "clareza organizacional" e "recompensas" apresentaram um grau de adequação razoável $(0,7516$ e 0,7140 , respectivamente).

De acordo com o teste de alpha de cronbach, as dimensões "conformismo" e "calor $e$ apoio" tiveram seus dados considerados não aceitáveis, pois obtiveram um alpha de 0,2745 e 0,6821, respectivamente. A dimensão "responsabilidade" também apresentou um resultado

\footnotetext{
9 (1) Discordo Totalmente, (2) Discordo Parcialmente, (3) Indiferente, (4) Concordo Parcialmente, (5) Concordo Totalmente.
} 
não aceitável $(0,6994)$, porém, optou-se por mantê-la na análise, pois seu alpha foi muito próximo a 0,7 (alpha aceitável).

Tabela 3 - Testes de validação dos dados

\begin{tabular}{cccccccc}
\hline Dimensões & $\mathbf{1}$ & $\mathbf{2}$ & $\mathbf{3}$ & $\mathbf{4}$ & $\mathbf{5}$ & $\mathbf{6}$ & $\mathbf{7}$ \\
\hline KMO & 0,5359 & 0,7516 & 0,5927 & 0.6278 & 0.6298 & 0.6792 & 0.7140 \\
ALPHA & 0,2745 & 0,8866 & 0,6821 & 0,7056 & 0,6994 & 0,7092 & 0,8474 \\
CRONBACH & & & & & & & \\
\hline
\end{tabular}

Fonte: Autores (2015).

Os resultados demonstram que a escolha das questões presentes nas dimensões 1 (conformismo) e 3 (calor e apoio) não foram adequadas para representar a dimensão do modelo de Kolb (KOLB et al., 1986), ou a dimensão teórica deve ser testada por outros trabalhos a fim de testar se o modelo é adaptável a cultura brasileira, uma vez que as dimensões 1 e 3 apresentaram resultados não satisfatórias nos dois testes, $\operatorname{KMO}(0,5359$ e 0,5927, respectivamente) e Alpha de Cronbach (0,2745 e 0,6821, respectivamente. Houve a tentativa de validar os constructos excluindo as questões que apresentaram cargas fatoriais mais baixas. Entretanto, os resultados continuaram insatisfatórios.

Após a realização dos testes de validação dos constructos, iniciou-se a análise dos fatores principais. Foram selecionados os componentes que apresentaram o eigenvalue maior que 1 , de acordo com o critério de Kaiser-Guttman. A coluna referente à variância explicada acumulada (VEA) dos componentes pertencentes a cada dimensão também foi analisada.

Tabela 4 - Dimensões do clima e suas variâncias explicadas acumuladas (VEA)

\begin{tabular}{ccccccccc}
\hline \multirow{2}{*}{ Dimensões } & \multicolumn{2}{c}{ Componente 1 } & \multicolumn{2}{c}{ Componente 2 } & \multicolumn{2}{c}{ Componente 3 } & \multicolumn{2}{c}{ Componente 4 } \\
& Autovalor & $\begin{array}{c}\text { VEA } \\
(\boldsymbol{\%})\end{array}$ & Autovalor & $\begin{array}{c}\text { VEA } \\
(\boldsymbol{\%})\end{array}$ & Autovalor & $\begin{array}{c}\text { VEA } \\
(\boldsymbol{\%})\end{array}$ & Autovalor & $\begin{array}{c}\text { VEA } \\
(\boldsymbol{\%})\end{array}$ \\
\hline Conformismo & 1,3783 & 35,8 & 1,0987 & 61,92 & & - & \\
$\quad$ Clareza & 5,1736 & 47,0 & 1,6634 & 62,15 & 1,1666 & 72,76 & & - \\
Organizacional & & & & & - & & - \\
Calor e Apoio & 2,2968 & 38,28 & 1,0431 & 59,17 & & - & & - \\
Liderança & 2,5694 & 42,82 & 2,0229 & 76,54 & & - & & - \\
Responsabilidade & 2,8320 & 47,2 & 1,5625 & 73,24 & & - & & - \\
Padrões & 2,4702 & 49,4 & 1,0560 & 70,52 & & - & \\
Recompensas & 4,7525 & 36,56 & 1,6033 & 48,89 & 1,3224 & 59,06 & 1,3027 & 69,08 \\
\hline
\end{tabular}

Fonte: Autores (2015). 
Após a definição dos constructos mais relevantes dentro de cada dimensão obtidos por meio da análise dos componentes principais, foram elaborados dois modelos de regressão. Esses modelos possibilitaram identificar dentre os principais componentes presentes nos constructos abordados, aqueles que tiveram a maior sensibilidade com a variável "score", variável cujos valores foram obtidos por meio da soma das médias encontradas em cada dimensão presente no modelo de Kolb (KOLB et al., 1986). O objetivo foi identificar os pontos mais relevantes nos quais o gestor deva depositar maiores atenções a fim de aumentar o valor da variável score e, consequentemente, melhorar o clima da empresa estudada, ou daquelas que adotarem este questionário como parâmetro para mensurar e/ou identificar os pontos relevantes do clima organizacional. A função regressão desenvolvida é dada por:

$$
\text { Score }=f c g_{11}+f c g_{12}+f c g_{21}+f c g_{22}+\cdots+f c g_{f i}
$$

A nomenclatura das variáveis explicativas foi criada seguindo o seguinte raciocínio: a letra "c" representa o componente, a letra "g" corresponde ao grupo/dimensão, o primeiro algarismo representa qual dimensão o componente é integrante ( 1 - conformismo, 2 - clareza organizacional, 3 - calor e apoio, 4 - liderança, 5 - responsabilidade, 6 - padrões e 7 recompensas); e o segundo algarismo aponta para qual componente pertencente à dimensão está sendo analisado. Veja a Tabela 5:

Tabela 5 - Análise da regressão robusta ${ }^{10}$ entre a variável score e os componentes dos constructos

\begin{tabular}{lcccc}
\hline Variável & $\begin{array}{c}\text { Todos fatores de autovalor }>\mathbf{1} \\
\text { Completo }\end{array}$ & $\begin{array}{c}\text { Constructos válidos } \\
\text { Significativas }\end{array}$ & Completo & Significativas \\
\hline$\beta \operatorname{cg} 11$ & $.103128 *$ & $.3558793 * * *$ & - & - \\
$\beta \operatorname{cg} 12$ & $.6353323 * * *$ & $.5298248 * * *$ & - & - \\
$\beta \operatorname{cg} 21$ & $.3729396 * * *$ & - & $.3448939 * * *$ & $.4344051 * * *$ \\
$\beta \operatorname{cg} 22$ & $.1983461 * * *$ & $.360802 * * *$ & $.358965 * * *$ & $.2669896 * * *$ \\
$\beta \operatorname{cg} 23$ & .0833154 & - & $.2480089 * * *$ & $.2458625 * * *$ \\
$\beta \operatorname{cg} 31$ & $.3000362 * * *$ & - & - & - \\
$\beta \operatorname{cg} 32$ & .1080527 & - & - & - \\
$\beta \operatorname{cg} 41$ & $.3799757 * * *$ & $.5282864 * * *$ & $.7482171 * * *$ & $.8751918 * * *$ \\
$\beta \operatorname{cg} 42$ & $.3940764 * * *$ & $.6126784 * * *$ & $.5795651 * * *$ & $.7391787 * * *$ \\
$\beta \operatorname{cg} 51$ & $.2973873 * * *$ & $.7195723 * * *$ & $.4324957 * * *$ & $.3310212 * *$ \\
$\beta \operatorname{cg} 52$ & .0795923 & - & .1567306 & - \\
$\beta \operatorname{cg} 61$ & $.5040509 * * *$ & $.507665 * * *$ & $.5151775 * * *$ & $.5711757 * * *$ \\
$\beta \operatorname{cg} 62$ & $.2374898 * * *$ & $.4157985 * *$ & $.2561425 * *$ & - \\
$\beta \operatorname{cg} 71$ & $.1778883 * *$ & $.3929195 * * *$ & .1150454 & -
\end{tabular}

10 Estimação robusta, segundo teste (WHITE, 1980).

ForSci.: r. cient. IFMG Campus Formiga, Formiga, v. 3, n. 2, p. 03-25, jul./dez. 2015. 


\begin{tabular}{ccccc}
$\beta \operatorname{cg} 72$ & $.1976224 * *$ & - & .1743203 & - \\
$\beta \operatorname{cg} 73$ & .0116304 & - & -.1412802 & - \\
$\beta \operatorname{cg} 74$ & .0516643 & - & $.2148585 * *$ & - \\
\hline $\mathrm{R}^{2}$ & 0.9982 & 0.9915 & 0.9869 & 0,9738 \\
\hline Test F & 0.000 & 0.000 & 0.000 & 0.000 \\
\hline $\mathrm{n}$ & 34 & 35 & 35 & 38 \\
\hline Estat vif & 5,07 & 2,09 & 2,91 & 2,19 \\
\hline$* * * 1 \%$ & $* * 5 \%$ & $* 10 \%$ & & \\
\hline
\end{tabular}

Fonte: Autores (2015).

$\mathrm{Na}$ primeira regressão foram selecionados todos os constructos que apresentaram eigenvalues maior que um. Porém, alguns constructos apresentaram uma multicolinearidade alta, problema previsto, visto que a variável dependente score é formada pela soma da média obtida em cada dimensão, tendo, portanto, uma alta relação com as variáveis explicativas, as quais também foram encontradas por meio da análise dos componentes principais de cada dimensão; e outros apresentaram baixa significância - p-value maior que 0,1 , optando, portanto, por excluí-los do modelo de regressão. Desta forma, o número de componentes (variáveis explicativas) presentes no modelo passaram de 17 para 9.

Analisando a sensibilidade das variáveis explicativas, foram observadas 4 de maior sensibilidade com a variável dependente score: cg51 (0.7195723) da dimensão "responsabilidade”, cg42 (0.6126784) da dimensão "liderança", cg12 (0.5298248) da dimensão "conformismo" e cg41 (0.5282864) também da dimensão “liderança".

Buscando identificar as questões mais relevantes em cada variável selecionada, foi analisada a carga fatorial das questões pertencentes a cada componente, como forma de subsidiar o gestor a identificar quais pontos devem ser melhorados objetivando influenciar, de forma mais contundente, o clima organizacional da empresa estudada.

Analisando a variável de maior sensibilidade (cg51), por meio da análise das cargas fatoriais (veja tabela 11 - apêndice B), percebe-se que a questão 30: "Eu me preocupo com o futuro desta empresa", foi a que obteve o maior valor $(0,4677)$. Portanto, é notória a relevância da temática responsabilidade do funcionário, pois aqueles que apresentam uma maior preocupação com o futuro da empresa tendem a obter maior nota na variável score, ou seja, no clima da empresa.

Outra dimensão destacada na análise refere-se a "liderança". A dimensão apresentou a segunda $(\operatorname{cg} 42)$ e a quarta (cg41) maiores sensibilidades dentre as variáveis do modelo (0.6126784 e 0.5282864 , respectivamente). Dentre as questões pertencentes a este constructo, aquelas que apresentaram a maior carga fatorial (veja a tabela 12 - apêndice B) foram a 25 - 
"Sinto-me a vontade em conversar sobre propostas de mudanças no meu trabalho com meus superiores" - no cg42 (0.5806) e a 23 - "O meu chefe imediato é um líder" - no cg41 (0.5630). Desta forma, percebe-se a relevância da temática de lideranças como fator de influência no clima organizacional da empresa estudada.

A última análise desse modelo de regressão é voltada à dimensão "conformismo", a qual apesar de não receber questões que pudessem melhor representá-la, teve um componente (cg12) que apresentou uma sensibilidade significante com a variável score. Por meio da análise da carga fatorial das questões pertencentes a este constructo (veja a tabela 8 - apêndice B), percebe-se que a questão de maior carga fatorial é a de número 1 (carga fatorial de 0.7292) do questionário: "Sinto-me satisfeito com o meu trabalho". Desta forma, sugere-se que em trabalhos futuros a referida questão deva ser mantida, mesmo que seja desenvolvida novas questões para esta dimensão, devido sua sensibilidade com o clima organizacional.

$\mathrm{Na}$ segunda regressão selecionaram-se os componentes com eigenvalues maiores que um e que pertenciam apenas aos constructos validados anteriormente, ou seja, foram desconsiderados os componentes pertencentes às dimensões "conformismo" e "calor e apoio".

Desta forma, a regressão inicial apresentou 13 variáveis (cg21 cg22 cg23 cg41 cg42 cg51 cg52 cg61 cg62 cg71 cg72 cg73 cg74), as quais não apresentaram problemas de multicolinearidade alta, porém algumas variáveis foram excluídas por apresentarem baixa significância ( $p$-value $>0,1)$, passando o modelo a ter 7 variáveis explicativas $(\operatorname{cg} 21 \operatorname{cg} 22$ $\operatorname{cg} 23 \operatorname{cg} 41 \operatorname{cg} 42 \operatorname{cg} 51 \operatorname{cg} 61)$.

Por meio da análise da sensibilidade das variáveis explicativas, percebe-se que novamente a dimensão "liderança" apresentou uma maior sensibilidade em relação a variável score tendo os componentes cg41 e cg42 as duas maiores sensibilidades do modelo $(0,8751918$ e 0,7391787 , respectivamente). Por meio da análise da carga fatorial das questões pertencentes a estes dois componentes, percebe-se que no componente cg41 as questões 22 "Eu confio plenamente no meu chefe imediato" e 23 - "O meu chefe imediato é um líder" foram as mais significativas com carga fatorial de 0,5445 e 0,5630, respectivamente. Em relação ao componente 2 da dimensão, as questões que apresentaram as maiores cargas fatoriais foram a 24 - "Tenho liberdade de conversar sobre propostas de mudanças no meu trabalho com meus superiores" e 25 - "Sinto-me a vontade em conversar sobre propostas de mudanças no meu trabalho com meus superiores" $(0,5794$ e 58,06). Desta forma, a dimensão 
"liderança" concretiza-se como extremamente relevante ao apresentar uma maior sensibilidade com a variável score, a qual é responsável por quantificar o clima da empresa.

Outra dimensão destacada pela sensibilidade foi a "padrões", representada pela dimensão cg61 (0,5711757). Por meio da análise da carga fatorial das questões pertencentes a esta dimensão (veja a tabela 9 - apêndice B), destacam-se as seguintes questões: 34 - “As condições de trabalho (iluminação, ventilação, espaço físico, móveis e utensílios) favorecem a execução das minhas atividades na empresa", 36 - "Os treinamentos realizados na organização são adequados e eficazes para a realização do meu trabalho", 37 - "Recebo informações e feedback da liderança sobre a qualidade do meu trabalho" e 38 - "Todos os processos necessários para as atividades da empresa x estão definidos e são conhecidos pelos funcionários" apresentando, respectivamente, as seguintes cargas fatoriais: 0,5576, $0,4778,0,43120$ e 0,4548 . Portanto, percebe-se que o fato dos funcionários serem treinados para desempenharem suas funções, estarem a par dos processos e de suas responsabilidades e receberem um feedback de seus superiores a respeito de seus desempenhos, exerce grande influência no clima da empresa, logo, são pontos chaves nos quais o gestor deve embasar suas ações a fim de propiciar um melhor clima organizacional para a empresa.

\section{CONCLUSÃO}

Conclui-se que a maior contribuição desta pesquisa está direcionada a redução da subjetividade do modelo de Kolb (KOLB et al., 1986) por meio da definição de questões que possibilitaram representar, através de testes estatísticos (KMO e Alpha de Cronbach), cinco dimensões: "lideranças", "responsabilidade", "padrões", "clareza organizacional" e "recompensas". Em relação às dimensões que obtiveram resultados não satisfatórios "conformismo" e "calor e apoio", sugere-se criar um maior número de questões, ou, caso necessário, criar outras questões e seguir os passos da análise feita nesta pesquisa, como forma de validá-las a fim de obter êxito em todas as dimensões.

A partir dos modelos de regressão criados entre os componentes de cada dimensão e de uma variável chamada "score" (a soma das médias obtidas em cada dimensão), identificouse os principais componentes que apresentam maior sensibilidade com essa variável. Assim, por meio da análise conjunta dos dois modelos de regressão, destacaram-se os seguintes pontos: I - a dimensão mais influente no clima da empresa estudada é a "liderança", pois esta obteve resultados relevantes nas duas regressões; II - a dimensão "padrões", destacada na 
análise da segunda regressão, demonstrou-se sensível ao clima da empresa. Nesse sentido, propõe-se aos gestores (líderes) trabalharem com mais afinco a criação e padronização de normas e processos, visto que a dimensão "padrões" - responsável por esses aspectos - foi a dimensão que obteve os menores índices na análise descritiva e demonstrou-se significativa no clima da empresa $X$.

Como limitação desta pesquisa, ressalta-se a situação em que a empresa se encontra processo demissionário - o que pode ter influenciado nas respostas dos funcionários, podendo ter subestimado ou superestimado o resultado. O número de respondentes também foi fator limitador, uma vez que esse número (44) foi inferior ao número de questões (51). Portanto, sugere-se a adoção de amostras mais representativas em quantidade.

Sugere-se para trabalhos futuros a replicação do questionário em outras empresas com o objetivo de confirmar a credibilidade das questões em representar as dimensões de Kolb et al (1986). Naquelas dimensões em que não se obteve êxito ("conformismo" e "calor $e$ apoio"), sugere-se modificar ou até mesmo desenvolver um maior número de questões e realizar os testes necessários de modo a validar o questionário em sua totalidade. Além disso, propõe-se a coleta de um número maior de informações de modo a possibilitar a realização de análises mais profundas a respeito do clima organizacional, por meio do cruzamento de variáveis que possam identificar relações entre si. Por fim, sugere-se, em caso de introdução de novas questão nas dimensões "conformismo" e "calor e apoio", manter a questão 1 "Sinto-me satisfeito com meu trabalho" na dimensão "conformismo". Esta questão apresentou a maior carga fatorial dentro do segundo componente identificado na referida dimensão por meio da análise dos componentes principais, o qual, por sua vez, apresentou uma das maiores sensibilidades com a variável "score." Torna-se relevante a replicação dos testes de adequação estatística nas novas questões, além da realização de uma nova análise de regressão visando identificar as modificações ocasionadas nas sensibilidades das variáveis explicativas (componentes principais) em relação a variável dependente "score", decorrentes das modificações feitas.

\section{REFERÊNCIAS}

CARAVAnTES, G. R.; PANNO, C. C.; KLOECKENER, M. C. Administração: teoria e processos. São Paulo: Pearson Prentice Hall, 2005. Disponível em: <http://ifmg.bv3.digitalpages.com.br/users/publications/9788576050261/pages/_5>.Acesso em: 04 jun. 2015. 
CARVALHO, K. M. C. D. Uma análise do clima organizacional em uma empresa varejista de móveis e eletros na cidade de picos - pi. 2011. (Monografia) - Curso de Administração - Universidade Federal do Piauí, Picos, 2011. Disponível em:

$<$ http://www.ufpi.edu.br/subsiteFiles/admpicos/arquivos/files/TCC-karina moura coqueiro de carvalho(1).pdf >. Acesso em: 05 jun. 2015.

COIMBRA, J. L. M. et al. Consequências da multicolinearidade sobre a análise de trilha em canola. Ciência Rural, v. 35, n. 2, p. 347-352, 2005. Disponível em:

<http://www.scielo.br/pdf/cr/v35n2/a15v35n2.pdf>. Acesso em: 23 out. 2015.

CRUZ, C. D.; CARNEIRO, P. C. S. Modelos biométricos aplicados ao melhoramento genético. Viçosa: UFV, 2003. 579 p.

DAMÁSIO, B. F. Uso da análise fatorial exploratória em psicologia. Avaliação Psicológica, v. 11, n. 2, p. 213-228, 2012.

DEMÉTRIO, C. G. B.; ZOCCHI, S. S. Modelos de regressão. Piracicaba: ESALQ, 2006.

FITZSIMMONS, J.; FITZSIMMONS, M. Administração de serviços: operações, estratégia e tecnologia de informações. Porto Alegre: Bookman, 2000.

FLOYD, F. J.; WIDAMAN, K. F. Factor analysis in the development and refinement of clinical assessment instruments. Psychological Assessment, v. 7, n. 3, p. 286-299, 1995.

HAIR, J. F. et al. Análise multivariada de dados. 6. ed. Porto Alegre: Bookman, 2009.

HERITIER, S. et al. Robust methods in biostatistics. Chichester, U.K.: John Wiley and Sons, 2009.

KOLB, D. A. et al. Psicologia Organizacional: uma abordagem vivencial. São Paulo, Atlas, 1986.

LAROS, J. A.; PUENTE-PALACIOS, K. E. Validação cruzada de uma escala de clima organizacional. Estudos de Psicologia, v. 9, n. 1, 2004.

LEITÃO, J. S. S.; GUIMARÃES, T. A.; ROSAL, M. A. A. Metodologia de diagnóstico de clima organizacional em ambiente de inovação tecnológica. In: ENCONTRO DA ASSOCIAÇÃO NACIONAL DE PÓS-GRADUAÇÃO EM ADMINISTRAÇÃO, 22., 1998, Foz do Iguaçu. Anais... Foz do Iguaçu, 1998.

LUZ, R. S. Gestão do clima organizacional: proposta de critérios para metodologia de diagnóstico, mensuração e melhoria. Estudo de caso em organizações nacionais e multinacionais localizadas na cidade do Rio de Janeiro. 2003. 182 f. (Dissertação) Universidade Federal Fluminense, Niterói, 2003. Disponível em: 
<http://www.bdtd.ndc.uff.br/tde_arquivos/14/TDE-2007-06-01T102808Z822/Publico/Dissertacao Ricardo Luz.pdf>. Acesso em: 03 jun. 2015.

OLIVEIRA, D. D.; CARVALHO, R. J.; ROSA, A. C. M. Clima organizacional: fator de satisfação no trabalho e resultados eficazes na organização. In: SIMPÓSIO DE EXCELÊNCIA EM GESTÃO E TECNOLOGIA, 9., 2012, Resende. [Anais]... Resende: [s.n.], 2012.

PASETTO, N. V.; MESADRI F. E. Comportamento organizacional: integrando conceitos da administração e da psicológica. Curitiba: Intersaberes, 2012.

PAYNE, R.L.; MANSFIELD, R. Relationships of perceptions of organizational climate to organizational structure, context and hierarquical position. Administrative Science Quartely, v. 18 , n. 4, 1977.

PUENTE-PALACIOS, K. E.; PACHECO, É. A.; SEVERINO, A. F. Clima organizacional e estresse em equipes de trabalho. Revista Psicologia, 2013. Disponível em: <http://pepsic.bvsalud.org/pdf/rpot/v13n1/v13n1a04.pdf>. Acesso em 04 jun. 2015.

ROBBINS, S. P. Comportamento Organizacional. 11. ed. São Paulo: Pearson Prentice Hall, 2005. Disponível em:

<http://ifmg.bv3.digitalpages.com.br/users/publications/9788576050025/pages/259>. Acesso em: 04 jun. 2015.

SANTOS, J. R. A. Cronbach's alpha: a tool for assessing the reliability of scales. Journalofextension, v. 37, n. 2, p. 1-5, 1999.

SANTOS, J. G. et al. Clima organizacional: um estudo de caso em uma empresa varejista em Campina Grande - PB. In: SIMPÓSIO DE EXCELÊNCIA EM GESTÃO E TECNOLOGIA, 7., 2010, Resende. [Anais]... Resende: [s.n.], 2010.

SBRAGIA, R. Um estudo empírico sobre o clima organizacional em instituições de pesquisa. Revista de Administração da Universidade de São Paulo, v. 18, n. 2, 1983.

SILVA, R. O. D. Teorias da administração. São Paulo: Pearson Prentice Hall, 2008. Disponível em: <http://ifmg.bv3.digitalpages.com.br/users/publications/97885760 50902/pages/_5>. Acesso em: 05 jun. 2015.

SIQUEIRA, F. C. D.; GODOY, L. P. Impacto do clima organizacional na qualidade dos serviços: estudo de caso em uma empresa de comunicação social. In: ENCONTRO NACIONAL DE ENGENHARIA DE PRODUÇÃO, 23., 2003, Outro Preto. Anais de resumos... Outro Preto: ABEPRO, 2003.

SOARES, J. J.; SOUZA, M. M. M. D. Diagnóstico na área de Recursos Humanos e clima organizacional. Diálogos Interdisciplinares, v. 3, n. 2, p. 49-70, 2014. 
SOUZA, E. L. P. Clima e motivação em uma empresa estatal. Revista de Administração de Empresas, v. 22, n. 1, 1982.

SOUZA, E. L. P. Percepção de clima conforme o escalão hierárquico. Revista de Administração de Empresas, v. 20, n. 4, 1980.

TAGLIOCOLO, C.; ARAÚJO, G. C. D. Clima organizacional: um estudo sobre as quatro dimensões de análise. In: SIMPÓSIO DE EXCELÊNCIA EM GESTÃO E TECNOLOGIA, 2011, Resende. [Anais]... Resende: [s.n.], 2011. Disponível em:

<http://www.anpad.org.br/admin/pdf/GPR1276.pdf > . Acesso em: 04 jun. 2015.

VARELLA, C. A. A. Análise de componentes principais. Seropédica: Universidade Federal Rural do Rio de Janeiro, 2008. Disponível em: <http://www.ufrrj.br/institutos/it/deng/ varella/Downloads/multivariada\%20aplicada\%20as\%20ciencias\%20agrarias/Aulas/analise \%2 0de\%20componentes\%20principais.pdf >. Acesso em: 05 out. 2015.

Recebido em: 06/11/2015.

Aprovado em: 09/11/2015.

Publicado em: 15/01/2016. 


\section{APÊNDICE A - Questionário proposto}

1. Sinto-me satisfeito com o meu trabalho.

2. Conheço as normas e procedimentos do meu setor de trabalho.

3. Sou informado (a) quando ocorrem mudanças na empresa.

4. Sinto que o excesso de formalismo não difículta o desempenho do meu trabalho.

5. Consigo entender claramente a estrutura de poder ou de departamentos que existe na Empresa X.

6. Confio na manutenção do meu cargo.

7. A empresa deixa claro a política de cortes e de contenção de despesas e de pessoal.

8. Estou a par de todas as mudanças que ocorrem na organização.

9. Consigo entender minha trajetória dentro da empresa e sinto orgulho desta.

10. Os meios de comunicação interna do Empresa $X$ me deixam bem informado sobre o que se passa dentro da empresa.

11. Consigo vislumbrar o crescimento da empresa nos próximos 5 anos.

12. Percebo que aqui o esforço é direcionado à satisfação do cliente.

13. Sinto que a organização se preocupa com o futuro.

14. Conheço a missão e visão da Empresa X.

15. Percebo que a empresa está preocupada com a satisfação dos seus funcionários.

16. Estou satisfeito com a estrutura hierárquica (chefes e subordinados) a que estou vinculado.

17. Costumo indicar a Empresa $X$ como alternativa de emprego para meus amigos e parentes.

18. Na minha opinião, a Empresa $X$ passa uma boa impressão para a população em geral

19. O relacionamento com meus colegas de trabalho favorece a execução das minhas atividades na empresa.

20. Na organização, todos estão dispostos a compartilhar informações.

21. A liderança busca me orientar visando que eu evite repetir os erros cometidos.

22. Eu confio plenamente no meu chefe imediato.

23. O meu chefe imediato é um líder.

24. Tenho liberdade de conversar sobre propostas de mudanças no meu trabalho com meus superiores.

25. Sinto-me a vontade em conversar sobre propostas de mudanças no meu trabalho com meus superiores.

26. Na empresa as pessoas sentem-se à vontade para sugerir/ apresentar críticas e melhorias.

27. O meu líder possui capacidade suficiente para exercer a sua chefia.

28. Eu conheço o organograma que é aplicado na Empresa $X$.

29. O organograma que é aplicado na Empresa X é o que funciona na realidade.

30. Eu me preocupo com o futuro desta empresa.

31. Tenho autonomia para resolver parte do meu trabalho.

32. Tenho e domino todas as informações necessárias para a execução do meu trabalho.

33. Eu conheço todos os processos necessários para o desempenho do meu trabalho.

34. As condições de trabalho (iluminação, ventilação, espaço físico, móveis e utensílios) favorecem a execução das minhas atividades na empresa.

35. Meu trabalho não é unicamente rotineiro.

36. Os treinamentos realizados na organização são adequados e eficazes para a realização do meu trabalho.

37. Recebo informações e feedback da liderança sobre a qualidade do meu trabalho.

38. Todos os processos necessários para as atividades da Empresa X estão definidos e são conhecidos pelos funcionários.

39. Se meu cargo for extinto, sou interessante para outra empresa. 
40. Estou preparado para assumir um cargo diferente do meu em outra empresa.

41. Considero que estou obtendo sucesso na minha carreira e na minha vida profissional.42.

Sou valorizado pela empresa.

43. Acho justo o meu salário atual.

44. O meu patrimônio é condizente com os esforços que tenho feito pela empresa.

45. Tenho perspectiva de crescimento na empresa.

46. Sou incentivado (a) a fazer capacitação, como cursos superiores, cursos, treinamentos, etc. pela empresa.

47. Sou lembrado na empresa pela importância do meu trabalho.

48. Tenho condições de ser aproveitado em outras instituições.

49. Consigo equilibrar meu tempo entre trabalho, família e vida social.

50. Tenho oportunidade de utilizar minhas habilidades no exercício de minhas funções.

51. Tenho um salário condizente com o mercado. 


\section{APÊNDICE B - Tabelas da análise das cargas fatorais}

Tabela 6 - Análise da carga fatorial da dimensão "responsabilidade"

Questões Componente 1 Componente 2 Inexplicável

\begin{tabular}{cccc}
\hline q28 & 0,4348 & 0,4147 & 0,1959 \\
q29 & 0,4323 & 0,4506 & 0,1535 \\
q30 & 0,4677 & 0,0118 & 0,3803 \\
q31 & 0,2696 & 0,215 & 0,7219 \\
q32 & $-0,4034$ & 0,5427 & 0,07904 \\
q33 & $-0,4122$ & 0,533 & 0,07493 \\
\hline
\end{tabular}

Fonte: Elaborada pelos autores.

Tabela 7 - Análise da carga fatorial da dimensão "liderança"

\begin{tabular}{cccc} 
Questões & Componente 1 & Componente 2 & Inexplicável \\
\hline q22 & 0,5445 & $-0,2235$ & 0,137 \\
q23 & 0,563 & $-0,2358$ & 0,07297 \\
q24 & 0,1665 & 0,5794 & 0,2497 \\
q25 & 0,1662 & 0,5806 & 0,2471 \\
q26 & 0,3491 & 0,4293 & 0,314 \\
q27 & 0,4574 & $-0,1932$ & 0,3869
\end{tabular}

Fonte: Elaborada pelos autores.

Tabela 8 - Análise da carga fatorial da dimensão "conformismo"

Questões Componente 1 Componente 2 Inexplicável

\begin{tabular}{cccc}
\hline q1 & 0,3344 & 0,7292 & 0,2843 \\
q2 & 0,5933 & $-0,2092$ & 0,4502 \\
q3 & 0,6517 & 0,1419 & 0,3707 \\
q4 & $-0,3338$ & 0,6359 & 0,418 \\
\hline
\end{tabular}

Fonte: Elaborada pelos autores. 
Tabela 9 - Análise da carga fatorial da dimensão "padrões"

Questões Componente 1 Componente 2 Inexplicável

\begin{tabular}{cccc}
\hline q34 & 0,5576 & $-0,0334$ & 0,2308 \\
q35 & $-0,2608$ & 0,8121 & 0,1355 \\
q36 & 0,4778 & 0,0975 & 0,426 \\
q37 & 0,4312 & 0,5602 & 0,2094 \\
q38 & 0,4548 & $-0,1268$ & 0,4721 \\
\hline
\end{tabular}

Fonte: Elaborada pelos autores. 